\title{
Sexuality Education to Adolescent Girls: A Panacea to Reducing the Incidence of 'Baby Factories' in South East Nigeria
}

Nkiru Christiana Ohia

Institute of African Studies, University of Nigeria, Nsukka

Christy N. Obi-Keguna

Department of Social Work, University of Nigeria, Nsukka

Uchenna M. Nzewi

Department of Science Education, University of Nigeria, Nsukka

Doi: 10.2478/mjss-2018-0122

Abstract

In Nigeria, sexuality education was given to young people as they undergo rites of passage at the onset of puberty. It is expected that as this no longer obtains, the immediate family and the school should take on the duty. In this study, the researchers sought to know if giving sexuality education to adolescent girls will serve as a panacea to reducing teenage pregnancies and 'baby factories' in South East Nigeria. The subjects for the study were 22 adolescents girls of between ages 12 to 17 who supplied narrative accounts of the sexual experiences that led to their getting pregnant. The result showed that information on sexuality is still not accessible to teenagers making them pawns in the hands of people that exploit their ignorance. Based on the result, it is recommended that the family and schools should make sexuality related information available to teenage girls.

Keywords: Baby factories, Sexuality Education, Virginity, Teenage Pregnancy, Taboo

\section{Introduction}

Production of babies purely for commercial purposes otherwise known as baby factories or baby harvesting, is currently the bane of the South East Nigeria, also known as Igboland. This practice negates the Igbo philosophy of the sacredness of the human being. The first case of baby factory in Nigeria was officially reported in 2006. The baby factories come in different guises- as orphanages, non-governmental organizations and rehabilitation homes for unmarried pregnant girls (Esadi, Achagh, llomuanya and Ogbuabor 2015). Huntley (2013) reported that sale of babies is the third most common crime in Nigeria. Baby factories are places where girls with unwanted or unplanned pregnancies go to take cover and then either willingly or forcefully, are tricked into giving up their babies for sale in the guise of adoption. In some cases, proprietors of these factories lure adolescent girls with material things and free abortions, and then employ them as baby making machines. The girls' are vulnerable and inexperienced. Most of them are gullible teenagers who got pregnant out of wedlock, a situation which carries strong social stigma in Igbo culture. Most of these girls got pregnant from having sex with their school mates who could not afford the fee to procure 
abortions for them. The National Agency for the Prohibition on Trafficking in Persons (NAPTIP), an agency fighting human trafficking in Nigeria revealed that some of these girls are forced to give up their babies for a token fee of twenty thousand Naira (about $\$ 40.00$ ) while the babies will then be sold to buyers between three hundred thousand Naira (about \$600) and five hundred thousand Naira (about $\$ 1,000$ ) depending on the sex of the baby. In some other cases, according to some rescued girls from the baby factories, they may not be pregnant at the point of getting to the factories but they are serially raped by men hired by the proprietor of the centres for the purpose of getting them pregnant. Another category of baby factory feeders according to Uduma (2011) are those who, driven by poverty, willingly put their wombs on lease as regularly as biologically possible to produce babies for sale.

The network of these baby factories is assuming such an alarming proportion that they are daily being raided by the police. For example Udeaja (2011) reported of the raid of two baby factories that pose as orphanages in Enugu. In June 2011, thirty two pregnant girls were rescued from a hospital, Cross Foundation, in Aba, Abia State of Nigeria. In October of the same year, about thirty pregnant girls were rescued from a hospital, Iheanyi Ezuma Foundation, in Uli, Anambra State of Nigeria. In 2012, according to Madike (nd) twenty pregnant girls and eight babies were rescued from a baby factory named Divine Mercy Motherless Home in Obosi, Anambra State. In another 'factory' named Double Research Clinic in Aba, Abia State, forty one girls aged between fifteen and twenty were rescued by men of Nigerian Security and Civil Defence. According to Mbawike (2015) nine pregnant girls were rescued at $9^{\text {th }}$ mile area of Enugu, Enugu State in June 2015, eight in Asaba Delta State in July 2015, and ten in Gariki area of Enugu in August 2015. This goes to show that the menace of baby factory is pervasive and not limited to a single location. Despite the apparent enormity and magnitude of this problem, little has been done in terms of empirical research to find out the mindset of these adolescents who are the feeders and suppliers of babies to baby factories and also ascertain if exposing them to sexuality education would have helped them to be more in control of their sexuality. This probing is necessary partly because matters relating to sex and sexuality are shrouded in secrecy, also girls who get pregnant out of wedlock are stigmatized in Igboland,. Again, baby factory business is illegal.

\section{Statement of the Problem}

For some time now, South East Nigeria has been in the news as a result of high incidence of teenage pregnancies and sale of babies. Baby markets, otherwise known as baby factories have been identified and found to be operative in the zone. Unfortunately, the people that supply the 'raw materials' (babies) for these factories are mostly adolescent girls who are or should be in secondary schools. As a result of globalization and improved access to the internet, young people are now being confronted daily by sexually explicit materials in print and electronic media. Consequently, there seems to be an outburst on sexual freedom and rejection or trivialization of the traditional conducts of sexuality. Being very inquisitive and always wanting to experiment, adolescents tend to unmask or unravel this mystery called sex by seeking information even from wrong sources which include uninformed peers and class-mates. It is expected that the fundamentals of human sexuality and reproduction should be taught both at home and in schools. It is also expected that the family which is the first agent of socialization should have taught these adolescents the Nigerian value for chastity and the value for respect and sanctity of human life, but this is not so. This failure has resulted to the many cases of teenage pregnancies and sale of children in the guise of adoption as many girls who were associated with baby factories were either found to be ignorant or wrongly informed of sex and sexuality. The purpose of this study therefore, is to investigate if the provision of sexuality education to secondary school girls will reduce teenage pregnancy and then act as a foil for baby factories in South East Nigeria.

Specifically, the study aimed at

1) Finding out why adolescent girls get involved with baby factories;

2) Identifying what constitute sexuality education;

3) Ascertaining if provision of sexuality education would reduce adolescents' pregnancy. 


\section{Research Questions}

1) Why do adolescent girls get involved with baby factories?

2) What constitutes sexuality education?

3) Would providing sexuality education to adolescent girls reduce the incidence of adolescents' pregnancy?

\section{Theoretical Framework}

This paper is hinged on the theories of Social Exchange and Situational Crime Prevention. These theories are considered most appropriate because of their basic principles. Social Exchange theory was propounded by Thibault and Kelly in 1952 and is based on exchange of rewards between actors. Thibault and Kelly (1952) theorize that people strive to minimize costs and maximize rewards and then base the likelihood of developing a relationship with someone on the perceived possible outcomes. When these outcomes are perceived to be more rewarding, people tend to develop a closer relationship with that person. The social exchange theory is based on the premise that human behaviour or social interaction is an exchange of activities -whether tangible or intangible (Homans, 1961). On a general note, West and Turner (2007), aver that the assumptions that social exchange theory makes concerning human relationships include:

- Humans seek rewards and avoid loss or punishment.

- Humans are rational beings (and as such make choices rationally).

- The standards that humans use to evaluate costs and rewards vary over time and from one person to another.

Summarily, this theory is relevant to this study because it helps to explain why a pregnant teenager goes to seek shelter in a baby factory to avoid stigmatization while on the other hand, a baby factory proprietor gives shelter to a pregnant girl in exchange for the baby when it is born. Again, the childless couple that needs a child parts with huge sums of money in exchange for a child that they desire.

On the other hand, Situational Crime Prevention theory was introduced by Ronald Clarke in 1980. This theory became popular in European academic circles in the 1990s, but has gained prominence in the United States only recently. The argument for a situational crime prevention theory was in the belief that a full understanding and control over sociological factors is unattainable. Proponents of this theory argue that it is necessary to forestall crime from occurring in the first place, as opposed to concerning themselves with detecting crime or punishing the criminal after the crime has been committed (Clarke 1980). They argue that crime prevention will be better achieved not by punishing criminals, but by influencing the-would be criminal's decision making process via various environmental and protection measures - situational factors (Clarke 1983). Hence, teenage pregnancy and the attendant sale of babies could be minimized by giving sexuality education to adolescents to help them take decisions that would forestall their having unwanted pregnancies in the first place.

\section{Method}

\subsection{Participants}

This study was carried out in South East Nigeria (Igboland), comprising of Abia, Anambra, Ebonyi, Enugu and Imo States. Participants for this study were twenty two adolescent girls who were out of school due to unwanted pregnancy (at the time of this study) and who have 'gone undercover' for the gestation period with the aim of covering up the pregnancy to save themselves the stigma associated with out of wedlock pregnancy, and also to save the face of the family by giving out the child for adoption (financial transactions are usually involved here) when it is born.

One of the researchers, a social worker contacted some serving or retired Social Welfare staff that she had related professionally with. They in turn linked the researchers with proprietors of maternity homes, private rehabilitation centers and medical doctors who sometimes harbor 
pregnant girls until they are delivered of their babies. The researchers chose to call these 'care givers'. These care givers were at first suspicious of the researchers' intentions (because of the illegality of their business), until they were convinced that whatever information obtained from the girls will be used purely for research purposes, and will be reported anonymously. The girls who were willing to be interviewed made themselves available while the consent of the care givers was sought. The consent of the care givers was necessary because the legal age in Nigeria is 18years, and none of the participants in the study was up to 18years at the time the study was carried out. Due to the clandestine nature of the study, and unwillingness of some of the identified pregnant girls, there was no sampling for the study and so, all the girls who consented to take part in the study were used. Although it was not the original intention of the researchers to interview the care givers, they also gave helpful insight to the researchers.

\section{Data Collection}

Data was collected through in-depth interviews conducted on different dates and locations between October 2015 and June 2016. These interviews lasted for about 30 minutes each but were not recorded as almost all the participants were not comfortable with tape recording their voices. Each of the researchers had to take notes or try to remember as much as possible. The researchers later compared notes and filled information gap. The interviews usually started with informing the participants of the purpose of the study and further appealing that they cooperate fully with the researchers. As most of these participants do not wish to be identified, consent was given verbally, and no consent form was filled. One of the researchers was a victim of teenage pregnancy when she was $15 y$ rs old, and giving this information to the participants often encouraged them to interact more freely with the researchers.

The interviews for this study were transcribed and checked for accuracy by the interviewers. Three coders did the initial level of analysis. First, the interview transcripts were coded independently. A process was followed in which case a code, mostly a word was assigned to each new idea represented in the new raw data. As new codes were identified, deductive processes guided the description of how the codes were interrelated. These key concepts continued to be developed and compared with the raw data until all the transcripts were coded. Also, all the transcripts were assigned codes independently by a minimum of one coder and all the codes were eventually reviewed by two more coders. The analysis was a representation of the agreement of all the coders (This process was adapted from Maggi et al 2014).

The second level of analysis was done using key words searches with the aid of the computer software QSR-NVivo to fish out the aspects wherein the respondents identified lack of sexuality education as causing their getting pregnant. Such excerpts were analyzed for their contents as well as themes.

\section{Results}

In discussing how and what led to their present condition, the accounts of most of the participants bothered on lack of sexuality education. Below are some of the excerpts.

\section{Participant 1 (14yrs)}

She was brought to the centre by her parents. She said she will be enrolled in another school after she delivers but her baby will be given out at birth as they do not want anybody to know that she had a child. Her parents are knights of the Roman Catholic Church and giving out the child will protect them from stigmatization.

I started menstruating when I was $13 y$ rs and 3months. My mother told me that I am now a woman and that I should know how I play with boys. She bought me sanitary pad and thought me how to use it. One day we went for debate and I became friends with a boy from another school and we fell in love. He told me that the only way to show that I really loved him was to have sex with him, and I did. It was just once. I did not know that I could get pregnant with that. I am just unlucky because some of my friends have had sex many times and did not get pregnant. 
When asked what her reaction concerning the 'arrangement' as regards her unborn baby is, she said she was made to understand that giving out the baby is the best option.

Mummy said it is better to have the child living than aborting the pregnancy since it is a sin to commit abortion. Keeping the baby will limit my chances of continuing my education and chances of getting married

\section{Participant 2 (16years)}

She is in Senior Secondary 3 and told her parents that she has gone to another school to take her West African School Certificate Examination. Her parents do not know that she is pregnant. She said that she will give out her baby for adoption as she does not want anybody to know that she had a baby. On how she got to know about the care giver, she said that her school Nurse linked her up with the caregiver. Her parents are rural farmers who will believe whatever she told them since they are not educated.

I thought it is safe to have sex two weeks after my menses. I have been doing that in the past and I never got pregnant. It has been working for me. I don't know why it is different now.

When prompted on how she got to know that having intercourse two weeks after her menses, she said it was her class girls that taught her.

\section{Participant 3 (14yrs)}

Her aunt who is a reverend sister took her in when her parents threw her out on knowing she was pregnant. She does not know what will happen to her baby when it is born and does not know if her parents will allow her to go back to school. On whether she had received any information regarding sex and relationships she said this:

My mother only told me that sex is painful and has to be endured. She said that it is only married people that do it, but my friends tell me that it is a sweet experience and if I do not start doing it on time; I will be having very painful child birth when I start having children. Many of them are doing it and are looking down on me. I started feeling like there is something wrong with me and I asked my best friend to help me get a boyfriend.

\section{Participant 4 (17yrs)}

She is in senior secondary school and helps her madam in her restaurant. She was brought to the care giver by her madam who promised to 'help' her take care of the problem so that her parents will not know that she had a baby. She is willing to give out her baby when it is born.

I help serve in the restaurant and madam told me to be good to customers. She told me that I will not get pregnant if somebody has sex with me while standing up that the semen will always flow out. It has worked for me for two years. This one is different and the problem is that all I know about the man is that he is a driver from Abuja. I don't know his name and how to contact him. Madam said that even if I get him that he will not take responsibility since he did not share a bed with me.

From the above narratives, it is obvious that nearly all the participants have either not received any or were given inadequate sexuality education, and so are uninformed or poorly informed of the implications of their sexual actions. Sexuality Education is any teaching that is capable of helping individuals to understand and prepare for all the experiences in life that have something to do with the physical, emotional, social growth and maturation in relation to sexuality and family life. The aim of Sexuality Education is to inculcate in the recipient, an understanding of positive sexuality views as well as providing information and skills about taking care of sexual health and making sound decisions about sexuality matters (Omeje and Nwosu (2007); Obanor and Omoera (2009) and Schidt, Abraham, and Kimberly 2015).

In an exposition of the importance of Sexuality Education, Nganda (nd) opines that the benefit of Sexuality Education lies in the fact that it addresses the biological, socio-cultural, and spiritual dimensions of sexuality from cognitive domain (information), affective domain (feelings, values and 
attitudes), and the behavioural domain (communication and decision making skills). Nganda maintains that such education will enable the adolescent to know herself/himself and so relate comfortably with others. The views of Ngada is very essential because when a teenager is comfortable in her relationship with others, she will be able to take and maintain her stand when she has sexual pressures. Experts in Social Psychology (Berganza, Peyrea and Aguila 1989; Nass and Fisher, 1994, and Masters, Johnson and Kolodny, 1995) reveal that adolescents have very strong sexual drives but unfortunately are so sexually immature that they are most times carried away by their sexual drives because they are uninformed or poorly informed of the implications of their sexual behaviours. Omeje and Nwosu (2007) endorsed this fact when they wrote that adolescents reach sexual maturity much earlier than they develop mental and emotional maturity and the social skills needed to appreciate the consequences of their sexual actions. For instance, Participant 5 (14yrs 8months) just finished writing Junior School Certificate Examination (equivalent of K9) when she was 'diagnosed' of being pregnant. Her parents, through the help of the family of the boy who got her pregnant, arranged that she goes to stay with a caregiver until she puts to bed. The boy is her first cousin and in Igbo culture, it is a taboo for them to have sexual relations. She said that was told that her baby died at birth. When asked if she saw the baby's remains, her response was that she neither the baby nor the remains as she was said to be too weak for days. However, the researchers strongly believe that her baby has been sold. She remained in the caregiver's home waiting for her parents to conclude arrangements to get her admitted to a new school to continue her education.

Her story:

I finished my exam in July and went to spend my holiday with my uncle in Port-Harcourt. My cousin usually helps me with my studies when his parents go to work. One day he wanted us to make love and I told him that I have not done it before and that I have not started menstruating. He informed me that I will not get pregnant since I had not started menstruating. I was worried that we were not supposed to make love since we are blood relations but he said it was in the olden days that such things were observed and that it doesn't matter since we were just playing and weren't planning to get married. I became sick about a month after and Mummy came to take me. When I was not responding to treatment and kept vomiting, a pregnancy test was done and the doctor said I was pregnant.

This is a clear case of lack of sexuality education. The young girl was deceived into believing that since she has not started menstruating, she cannot possibly get pregnant.

As a result of the notoriety sale of babies and human trafficking attracted to Nigeria, an agency, National Agency for the Prohibition of Trafficking in Persons (NAPTIP) was established in 2003. This agency has been swooping on baby factories but their activities have not abated. This is so because of the lucrative nature of the business, and the fact that most of the care givers believe that they are helping humanity. They feel that it is better to give a baby a chance to live than to have it aborted or dumped and left to die. Below is a response by one of the care givers.

\section{Caregiver 1}

I was a victim of teenage pregnancy. I am not married today because of that. I don't want any girl to suffer like me. This is why I am helping pregnant girls. In those days the parents usually threw a pregnant girl out or force her into untold hardship and loveless marriage with the result that many girls resorted to taking concoctions or having unsafe abortions thereby losing their lives in the process. Those who could not procure abortions hid their pregnancies and later threw the child away. Since we started helping young girls, you hardly get cases of dumping of new born babies.

The above reaction is strongly linked with the stigma associated with out of wedlock pregnancy. In many African societies according to Uchendu (1965), sexual relations and procreation are only allowed in marriage or concubinage. As a result of this, any pregnancy outside these two institutions are vehemently objected to. In fact, retaining virginity until marriage was the norm as this was a way of securing a marriage. A departure from this norm attracted butts and stigmatization so much so that post wedding night bed sheet inspection was used to determine a bride that came to her husband as a virgin. This means inspecting the bridal bed after the wedding 
night for traces of blood which is caused by broken hymen. If a bed sheet is seen to be stained with blood, it is a proof that the bride came to her husband as a virgin. If not, it is a clear indication that the bride has had sexual intercourse prior to her marriage. To avert the stigma associated with out of wedlock intercourse and pregnancy, teenagers with unwanted pregnancies, either seek abortion, hide the pregnancy and later throw the baby away or, as the case is presently, find safe haven in 'baby factories'. This is why nearly all cases of sale of babies are linked to unmarried teenagers in a bid to hide their conditions for fear of the stigma associated with having a children outside the approved social institutions. Supporting this view, Link and Phelan (2001) revealed that fear of discrimination and stigma is responsible for most social problems.

Caregiver 2 has this to say:

My rehabilitation Centre is fully registered with the appropriate authority and I do not do illegal adoption. There are many childless couples who need children to save their marriages. It is only human to encourage a pregnant girl not to get involved in abortion since many families out there are willing and have the resources to give her child a good life. Our culture opposes wasting human life and as far as I am concerned, getting pregnant outside marriage is bad enough, adding an abortion to it makes it worse.

It is not surprising to get this reaction from the care givers because in South East Nigeria (Igboland), it is believed that a childless marriage is a failed marriage. According to Ohia and Azikiwe (2013), African marriages are not based on romantic love. Procreation is the major reason for contracting marriages and when a couple fails to bring forth children, there is a lot of pressure from parents and in-laws. This being the case, many women go to the extent of faking pregnancy while arranging for an opportunity to adopt or to buy a child to protect their marriages. On the other hand, Nigerian society is patriarchal in nature. Descent and inheritance pattern is mostly through the father and so any woman that does not bear a male child is not regarded as having a 'child' no matter the number of girls she has. Most times, the family if not the husband, arranges for another wife that will bear male children or one of the daughters is regarded as male and she stays back to bear children that will carry on the family name (Amadiume,1987) .

Expressing concern over the escalating trend in baby factories in Nigeria, ( Uduma, 2011; Huntley, 2013; Onuoha, 2014; and Eseadi et al, 2015) identified poverty as the root cause of proliferation of baby factories in South East Nigeria. With the low per capita income of most parents in the country, they find it difficult to adequately provide for their children. As if in agreement to this notion, another care giver said:

Many girls often commit suicide when they get pregnant because adding another mouth to be fed in some families is a problem. Is it a girl that got pregnant in the first place because she got somebody that helped her out of a small personal need that you now expect to be saddled with the burden of rearing a child? Instead of folding our hands and allowing both mother and child to die, we usually rehabilitate the mother and help her to be useful to herself while the baby is given a chance to live.

Closely related to this is lack of values in the society. The traditional African values for hard work, respect for sanctity of life, love and promotion for family name have been watered down and replaced with excessive quest for money and material things.

Given that the 'raw materials' for these baby factories are mostly girls between the ages of 14 to 20 who inadvertently find themselves with unplanned pregnancies, the researchers argue that if the girls had received adequate and thorough Sexuality Education, they may have been equipped with the skills of knowing the consequences of their sexual actions. Sexuality Education would also have exposed them to the socially accepted values, views, and aspects of sexuality. Sexuality Education was introduced in Nigerian schools in 2001, according to Madunagu (2005) but unfortunately, there is research evidence (Akande and Akande 2007; Dienye, 2011; Nakpodoi, 2012; and Adetunji, 2013) that it is not offered in schools, mostly because some parents and churches oppose it. For example, the International Technical Guidance of the UNESCO lamented that in spite of the clear and pressing need for effective school based sexuality education, this is still lacking in most countries. According to them, this could be attributed to perceived or anticipated 
resistance resulting from misunderstandings about the nature, purpose and effects of sexuality education by parents and the churches. However, many churches rather give marriage and family life education for intending couples.

\section{Discussion of Findings}

The findings of this study reveal that lack of sexuality education is the major cause of unwanted pregnancy in adolescents. It is expected that as the communal nature of the society is giving way to more nuclear one due to movement to townships, and the previous arrangement of giving this education by the extended family members no longer holds, the immediate family and the school should take on the duty. Unfortunately, as a result of acculturation and the change in gender roles in families, mothers now take on paid employment making them send their children to school even as early as two years. This make children spend more time with their teachers and their classmates than they do with their parents and siblings with the result that those things that the child should get from the family are lost. Since the greater responsibility of child upbringing is gradually resting on the school, it is expected that the school should be giving a more holistic education to these children in their care, and this includes giving Sexuality Education. Unfortunately, both the family and the school are failing in this regard. This failure according to some studies carried out by some Sociologists (Tieno (1992), Melgosa (2001), and Ohia, 2016) is because some parents erroneously believe that knowledge about sexuality matters will lead to curiosity and experimentation but it has been known that sexuality education teaches teenagers to have the skills that will help them stay away from behaviours that will predispose them to getting pregnant. Due to ignorance or misinformation about sexuality matters, teenagers have been known to make very serious and sometimes life threatening mistakes.For example, one of the adolescents interviewed said ' $m y$ friend told me that if I drink salt water after sex, it will kill all the sperm' yet another, when asked why she indulged in unprotected sex said, 'my classmates said that drinking potash solution will not allow somebody to get pregnant'.

The result of flagrant misuse and abuse of sexuality and unchecked sexual drive include emotional breakdown, sexually transmitted diseases, unplanned pregnancies, abandoned babies, and recently, the booming 'baby factories' making Nigeria one of the most notorious countries in the world. For example, Umoh (1986) as cited by Obiekea, Ovri and Chukwuma (2013) found premarital sex and pregnancy to be the major causes of school drop-out in a study conducted on school drop-out in some selected secondary schools in Kwara, Cross River and Rivers States that used principals and students as respondents. In another study aimed at addressing the health needs of adolescents in Nigeria, Godswill (2012) revealed that many teenagers believe that pregnancy cannot occur after just one exposure to sexual activity. They are surprised to find themselves with unwanted and unprepared for pregnancy the first time they experiment with sex eg 'It was just once. I did not know that I could get pregnant with that. I am just unlucky because some of my friends have had sex many times and did not get pregnant'

African societies believe that human sexuality is the very essence of the society, and so influences and determines the perpetuation of the society, and if allowed unchecked, may drive individuals and societies to ruin. This is why every African society has a set of rules that guide and regulate sexual activities as they believe that individuals do not have monopoly of their sexuality. Through songs, idioms, proverbs and folktales, they were made to know that their bodies are for fecundity and should be kept well and that children are gifts from the gods and should not be sold in the market. Traditionally, pre-marital chastity (especially for girls) was emphasized. The virginity of the bride at marriage was the proof of her good upbringing. Mothers, as revealed by Amadiume (1987) had the responsibility of guarding their daughters' virginity and they were hugely rewarded by their in-laws if their daughters were found to be 'intact' on their marriage night. For example, Achebe (1960), in No Longer at Ease, narrated how a goat and other presents were sent to Okuata's mother because her daughter was 'found at home' (was found to be a virgin) on her wedding night, while Ogbanje, Omenyi's mother was sent a matchet to cut 'the bush on either side of the highway between her daughter's thighs' because her daughter had compromised her own virginity. Although custom demanded some restraint from young men, it was not an issue if a man 
losses his virginity before marriage. In fact, such men were secretly admired by other fellow men.

Laying credence to the above view, Tieno (1992) maintains that Sexuality Education would give an idea about what young people will experience in their own bodies with maturity, and cautions that lack of knowledge on sexuality issues may lead to sexual misadventure that has undesirable consequences. Also stressing the need for Sexuality Education, Melgosa (2001) argued that the fundamentals of human sexuality and reproduction should be taught in schools. This argument is based on the premise that such exposure would equip and allow adolescents to become familiar with the mystery of life and the risks involved in unguarded sexual act. In conclusion, the authors, basing their argument on Situational Crime Prevention Theory, believe that with adequate sexuality knowledge, young people will adopt responsible attitudes to their dressing, their social relationships, values, and all sexual matters. If this is achieved, the life line of 'Baby Factories' will be stifled and the social problems of teenage pregnancy, child trafficking, sale of babies and shoddy adoptions which negate the African value of respect and sanctity of human life will be eliminated.

\section{References}

Adetunji,S.O.(2013). Attitudes of parents in metropolis of Lagos towards inclusion of Sexuality Educationin the school curriculum. Journal of Studies in Social Sciences 3 (2) 129-137.

Akande, A.A and Aknde, T.M. (2007). Knowledge and perception of Sexuality Education among students of a rural secondary school in Kwara State. Nigerian Medical Practitioner 52 (3) 55-59.

Amadiume, I. (1987) Male daughters, female husbands: Gender and sex in an African society. London:Zed Books Ltd.

Amanze, J.N. (2003). Demytholizing African conceptions of human sexuality: A gateway to prevention of and eradication of HIV and AIDS in Africa. www.inerela.org/2000/07. Retrieved 10th August 2015.

Berganza, C.E., Peyre, C.A. and Aguila G. (1989). Sexual attitudes and behavior of Guatemalalan teenagers: Considerations for prevention of adolescent pregnancy. Adolescence, 24(94) 327-337.

Clarke, R. V.(1980) Situational crime prevention: Theory and practice. The British Journal of Criminology. 20 (2) 136-147.

Clarke, R. V.(1980) Situational crime prevention: Its theoretical basis and practical scope. Crime and Justice 4 (1) $225-256$

Dienye, V.U.(2011).The educational and social implications of Sexuality and Sex Education in Nigerian schools. African Journal of Social Sciences 1 (2) 11-19.

Homans, G. (1961). Social Behavior. New York: Harcourt, Brace \& World.

Huntley, S.S. (2013). The phenomenon of baby factories in Nigeria as a new trend in human trafficking. International Data Base. Retieved on $29^{\text {th }}$ October, 2015 from www.internationalcrimesdatabase.org/upload/documents/20131030t045906- ICD\%2520Brief\%25203\% .

Eseadi,C., Achagh, W.,Ilomuanya,A., and Ogbuabor, S. (2015) Prevalence of baby factories in Nigeria: An emergent form of child abuse, trafficking and molestation of women. International Journal of Interdisciplinary Research Method 2(11) 1-12.

Link, B.G. and Phelan, J.C. (2001). Conceptualizing Stigma. Annual review of Sociology, 27(1)366-385.

Madike, I. (nd). Child trafficking: How and why they do it. http://nationalmirroronline.net/new/child-traffickinghow-and-why-they-do-it/. Retrieved on $12^{\text {th }}$ August, 2015.

Maggi, S. Lovato, C. Y., Hill, M.,Johnson, J.L., Ratner, P.A. \& Shoveller, J.A (2014).Adolescents' perceptions of parental influences on their smoking behavior: A content analysis. Youth and Society, 46(1), 132-149 DOI:1011700441184114344

Masters, W.H, Johnson, V.E and Kolodny, R.C (1995). Human Sexuality. New York: Harper Collins College Publishers.

Melgosa, J. (2001). New Life Style To Adolecsents and Parents. New York:International University Press.

Nakpodia, E.D.(2012).The relevance of sex education in secondary schoolcurricula in Abraka metropolis, Delta State Nigeria. Scholarly Journal of Business Administration 2 (2) 36-41. Accessed from www.scholarlyjournals.com/SJBA on $5^{\text {th }}$ July, 2014.

National Agency for the Prohibition of Trafficking in Persons News (2010). 2(2) August-October

Nass, G.D. and Fisher, M.P.(1994). Sexuality Today. Boston: Jones and Barlett Publishers.

Nganda, S. (nd). Sex Education: Do our teens need it? www.arsrc.org/downloads/uhsss/nganda.Retrieved $10^{\text {th }}$ August, 2015.

Obanor, M and Omoera O. (2009). Refocusing Sexuality Education Among Nigerian Adolescents: The Theatre Option http://www.aaukpoma.edu.nis. Retrieved 1st June, 2010. 
Obiekea, P.O., Ovri, F. B. and Chukwuma, E.T. (2013). Sexual Education: An intervention and social adjustment programme for youths in secondary schools in Nigeria. African Research Review 7(1) 322339.

Oghenekaro, O. (2013). Orient Daily: Director calls for life sentence for operators of baby factories Retrieved from http://orientnewspapper.com/director-calls -for-life-sentence-for-operators -of -baby-factories on $12^{\text {th }}$ January, 2014.

Ohia,N.C. and Azikiwe, U. (2013)The church, sexual harassment and abuse of women. In Religion and Gender Based Violence: The West African Experience. Amengo-Etego,R. and Odudoye, M.(eds). Ghana: Legon Theological Series 83-98.

Omeje, J. and Nwosu, E. (2007). Sexuality Education and the role of women in training of schooling adolescents: Implication for effective service delivery. In B.G. Nworgu (ed) Optimization of Service Delivery In the Education Sector: Issues and Strategies. Nsukka:Universal Trust Publishers.

Onuoha, F.C. ( 2014) Wares of trade:Understanding evolving baby factory and trafficking in Nigeria. Unpublished conference paper presented at the $5^{\text {th }}$ international conference on crime reduction and criminal justice, organized by the Institute of Security Studies, Johannesburg between $14-15^{\text {th }}$ August.

Schmidt, S.C, Abraham, W., and Kimberly, J.H. (2015). Evidence-based Sexuality Education Program in schools: Do they align with National Sexuality Education standards? American Journal of Sexuality Education 10 (2) 117-195.

Thibault, J and Kely, H. (1952). The social psychology of groups. New York: John Wiley \&sons.

Tieno, A.S (1992). Off our backs: Sexuality and popular culture. New York: Gale Group.

Uchendu, V.C. (1965). Concubinage among Ngwa Igbo of Southern Nigeria. Africa: Journal of International African Institute 35 (2) 187-197.

Udeaja, G. (2011). Nigerian Baby Factory Raided. The Guardian June,2 2011 p.7.

Uduma, Kalu (2011) How child trafficking network operates in South East. www.vanguardngr.com/2011/07/howchild-trafficking-network-operates-in south-east. Assesed 13th September,2015.

West, R., \& Turner, L. (2007). Communication Theory: Analysis and Application (3 $3^{\text {rd }}$ ed.). New York :McGraw Hill. 